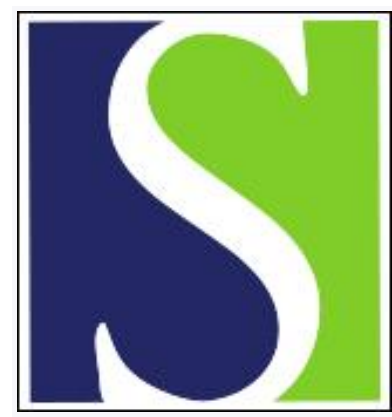

Scand J Work Environ Health 2015;41(3):247-258

https://doi.org/10.5271/sjweh.3490

Published online: 16 Mar 2015, Issue date: 01 May 2015

Relationships of neurosensory disorders and reduced work ability to alternative frequency weightings of hand-transmitted vibration

by Bovenzi M, Prodi A, Mauro M

This is the first epidemiological study with a prospective cohort design that investigates the relationships of neurosensory disorders and reduced work ability to vibration exposure assessed by means of a set of alternative frequency weightings of hand-transmitted vibration (HTV). The study provides epidemiological support to the choice of appropriate frequency weightings of HTV by ISO standards.

Affiliation: Clinical Unit of Occupational Medicine, Department of Medical Sciences, University of Trieste, Centro Tumori, Via della Pietà 19, I-34129 Trieste, Italy. bovenzi@units.it

Refers to the following text of the Journal: 2011;37(3):244-252

Key terms: alternative frequency weighting; cohort study; exposure-response relationship; finger numbness; frequency weighting function; hand-transmitted vibration; neurosensory disorder; quantitative sensory testing; sensorineural symptom; vibration; vibration exposure; work ability

This article in PubMed: www.ncbi.nlm.nih.gov/pubmed/25775437

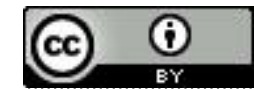




\title{
Relationships of neurosensory disorders and reduced work ability to alternative frequency weightings of hand-transmitted vibration
}

\author{
by Massimo Bovenzi, MD, ${ }^{1}$ Andrea Prodi, MD, ${ }^{1}$ Marcella Mauro, MD ${ }^{1}$
}

\begin{abstract}
Bovenzi M, Prodi A, Mauro M. Relationships of neurosensory disorders and reduced work ability to alternative frequency weightings of hand-transmitted vibration. Scand J Work Environ Health. 2015;41(3):247-258. doi:10.5271/sjweh.3490
\end{abstract}

\begin{abstract}
Objective This cohort study aims to compare the performance of alternative frequency weightings of handtransmitted vibration (HTV) for the assessment of the exposure-response relationships for neurosensory disorders and reduced work ability among HTV-exposed workers.

Methods In a 3-year follow up study, the occurrence of neurosensory symptoms and reduced work ability, and the response to quantitative sensory testing (grip force, manipulative dexterity, touch sensation) were investigated in 249 HTV-exposed workers and 138 healthy controls. Among the HTV-exposed workers, the sensory outcomes were related to measures of daily vibration exposure expressed in terms of 8-hour energy-equivalent frequency-weighted acceleration magnitude $[A(8)]$. To calculate $A(8)$, the acceleration magnitudes of vibration were weighted by means of four alternative frequency weightings of HTV.

Results The occurrence of neurosensory symptoms, reduced work ability, and abnormalities of sensory tests was greater among the HTV-exposed workers than the controls. Among the HTV-exposed workers, the deterioration of neurosensory outcomes and the reduction of work ability increased on par with the measures of vibration exposure. Exposure-response models revealed that the four alternative frequency weightings of HTV provided the same predictions for the probability of finger numbness among the exposed workers (observed 36\% versus predicted 32\%)

Conclusions The findings of this study revealed significant dose-response relationships between measures of vibration exposure, sensory disorders, and reduced work ability among the HTV-exposed workers. There were no differences in the prediction of finger numbness between measures of vibration exposure calculated with alternative frequency weightings of HTV.
\end{abstract}

Key terms cohort study; exposure-response relationship; finger numbness; frequency weighting function; quantitative sensory testing; sensorineural symptom; vibration exposure.

Occupational exposure to hand-transmitted vibration (HTV) is associated with an increased risk of vascular, neurological, and musculoskeletal disorders in the upper limbs of the exposed workers, collectively known as the hand-arm vibration syndrome (HAVS) (1). The vascular component of HAVS is represented by a secondary form of Raynaud's phenomenon called vibration-induced white finger (VWF); the neurological component is characterized by a peripheral, diffusely distributed neuropathy with predominant sensory impairment; the musculoskeletal component includes abnormalities in the muscle, tendon, bones, and joints of the upper extremities.
In the international standard ISO 5349-1 (2) for the evaluation of human exposure to HTV, it is said that the exposure-response relationship proposed in an annex to the standard may be used for the assessment of all biological effects of HTV. Three measures of exposure to HTV are used to outline the ISO exposure-response relationship: vibration magnitude, daily exposure duration, and years of exposure. The acceleration magnitude of vibration is frequency weighted over the working frequency range specified in ISO 5349-1 (one-third-octave band frequencies from $6.3-1250 \mathrm{~Hz}$ ) by means of a weighting function (called $W_{\mathrm{h}}$ ) which assumes that the sensitivity of the finger-hand-arm system is approximately proportional

1 Clinical Unit of Occupational Medicine, Department of Medical Sciences, University of Trieste, Centro Tumori, Via della Pietà 19, Trieste 34129, Italy.

Correspondence to: Professor Massimo Bovenzi, MD, Clinical Unit of Occupational Medicine, Department of Medical Sciences, University of Trieste, Centro Tumori, Via della Pietà 19, I-34129 Trieste, Italy. [E-mail: bovenzi@units.it] 
to vibration acceleration below $16 \mathrm{~Hz}$, and decreases in inverse proportion to frequency from $16-1250 \mathrm{~Hz}$. It has been argued that it is unlikely that one frequency weighting is suitable for the assessment of all disorders caused by HTV because of the different pathophysiological mechanisms underlying the neurovascular and musculoskeletal components of the HAVS (3).

In a previous study, we tested the performance of four alternative frequency weightings to predict the occurrence of VWF in a cohort of HTV-exposed workers recruited within the EU project VIBRISKS $(4,5)$. It was shown that measures of daily vibration exposure, which give relatively more weight to intermediate and high frequency vibration, were more appropriate for assessing the probability of VWF than a measure based on the current ISO frequency weighting. As a result, a draft of technical document is now circulating to ISO experts to consider possible alternative frequency weightings for vibration-induced vascular injuries.

Currently it is unknown whether these alternative frequency weightings of HTV may be valid also for vibration-induced neurosensory disorders. It has been suggested that peripheral sensorineural symptoms may cause more discomfort and disability than VWF since the latter is episodic and usually triggered by cold exposure, while sensory disturbances may be persistent and interfere with work and life activities $(1,6)$.

The aim of this longitudinal study was to investigate the exposure-response relationships of HTV exposure to peripheral neurosensory disorders and reduced work ability in the VIBRISKS cohort. The frequencydependence of neurosensory outcomes to vibration was evaluated by comparing exposure-response models constructed with the alternative frequency weightings previously used to predict VWF.

\section{Methods}

\section{Interview and medical investigations}

The cohort included 249 HTV-exposed workers (215 forestry operators and 34 stone workers) and 138 control men employed at the same companies and unexposed to HTV (129 maintenance operators, 5 inspectors, 4 supervisors). They were investigated at the cross-sectional survey and over annual follow-up investigations carried out in the same seasonal period (autumn-winter 2003-2007). Of the HTV-exposed workers, 177 participated in three follow-ups, 36 in two follow-ups, and 36 in one follow-up survey. Of the controls, 99 participated in three followups, 19 in two follow-ups, and 20 in one follow-up survey.

All HTV-exposed workers continued to work with vibratory tools during the follow-up.
All subjects gave signed informed consent to the study, which was approved by the local health authorities.

A complete description of the cohort and the study design has been reported in a previous paper (7).

The HTV-exposed workers and the controls were interviewed on their personal, work, and health histories using a structured questionnaire developed within the EU research project VIBRISKS (4). The subjects underwent a complete physical examination focused on the vascular, neurological, and musculoskeletal systems of the upper limbs.

Each subject was asked if he suffered from persistent tingling (pricking sensation) and/or numbness (impaired cutaneous perception) in the fingers and hands. Case definition did not include subjects who reported temporary presence of tingling or numbness occurring while or after working with vibratory tools, during or following episodes of VWF or exposures to cold environment (8). The diagnosis of VWF was based on the findings of the medical interview assisted by color charts according to the criteria established by the Stockholm Workshop 1994 (5).

Reduced work ability caused by finger/hand symptoms was investigated by means of the following questions: (i) In the past 12 months, did finger/hand symptoms interfere with any work activities? (ii) In the past 12 months, did finger/hand symptoms affect your work performance? (iii) Was there any reduction in your work output in the last 7 days due to finger/hand symptoms?

The response options for the questions about selfreported work ability were yes or no.

The diagnosis of suspected carpal tunnel syndrome (CTS) was made according to the consensus criteria for the classification of CTS symptoms/signs in epidemiologic studies (9). In the VIBRISKS protocol (4), all the following criteria were required for the "clinical suspicion" of CTS: (i) classic/probable symptoms (numbness, tingling, burning or pain in at least two of digits 1, 2 or 3); (ii) nocturnal symptoms; and (iii) positive physical examination (Tinel's test or Phalen's test).

\section{Quantitative sensory testing}

Grip strength. The maximal grip strength of the hand was measured by a Jamar ${ }^{\circledR}$ hydraulic dynamometer set (model 5030J1). The subject was seated with his elbow flexed to $90^{\circ}$, wrist in neutral position and forearm supported on a bench. He was instructed to squeeze the dynamometer three times with each hand with a 10 -second interval between each attempt. The average value of the three grip strength attempts was recorded and expressed in Newton.

Manipulative dexterity. Manipulative dexterity was investigated by means of the Purdue pegboard testing method 
(Lafayette Instrument Co ${ }^{\circledR}$, USA). The test was administered according to a standardized test procedure (4). Starting with the dominant hand, the subject had to pick up pins from a cup on the corresponding side of the board and place as many pins in the holes as possible within 30 seconds. The subject completed the test once for each hand and once for both hands together. During the test procedure, there was no restriction to the visual input (board and pins) of the subject. Manipulative dexterity was scored on the basis on the number of pegs placed in the holes with the dominant and non-dominant hand and both hands.

Cutaneous sensation. Semmes-Weinstein's monofilaments with hair diameter of $0.127-1.143 \mathrm{~mm}$ (corresponding to a force of $0.068-447 \mathrm{~g}$, respectively) were used to evaluate cutaneous sensation (Touch Test ${ }^{\mathrm{TM}}$ Sensory Evaluator sizes 2.83-6.65, Stoelting Co ${ }^{\circledR}$, IL, USA). Touch thresholds were measured at the palmar surface of the tip of the $2^{\text {nd }}$ and $5^{\text {th }}$ fingers of both hands to evaluate the function of the median and ulnar nerves, respectively. With the subject looking away, the filament was pressed at a $90^{\circ}$ angle against the skin until it bowed. It was held in place for 1.5 seconds and then removed. The test began with the $0.068 \mathrm{~g}$ monofilament, which was applied in the same location up to three times to elicit a response. If the subject did not feel the stimulus, the test continued with the next larger monofilament and the application procedure was repeated. The monofilament test was administered by the same health professional at both the cross-sectional and follow up investigations.

\section{Measurement and evaluation of vibration exposure}

Vibration was measured on the forestry workers' brush and chain saws and the stone workers' grinders, polishers, and inline hammers. Details on vibration measurements are reported elsewhere (5). Vibration was measured in three orthogonal directions $(x, y, z)$ according to the procedure recommended by ISO 5349-1 (2). Vibration magnitudes were expressed as root mean square (rms) accelerations over the frequency range 1-4000 $\mathrm{Hz}$ as defined in international standard ISO 8041 (10).

Acceleration magnitudes were weighted using the frequency weightings displayed in figure $1(11): W_{\mathrm{h}}$ is the frequency weighting specified in ISO 5349-1 (2); $W_{\mathrm{h}-b l}$ is the band-limiting component of $W_{\mathrm{h}}(10) ; W_{\mathrm{hf}}$ is a frequency weighting based on biodynamic studies of finger vibration power absorption (12); and $W_{\mathrm{hT}}$ is a frequency weighting based on a Japanese study of VWF prevalence in worker groups investigated from 1957-1977 (13).

Compared to the ISO frequency weighting $\left(W_{\mathrm{h}}\right)$, the additional candidates for frequency weighting of HTV give more weight to intermediate and high frequency vibration, although the difference in weighting between two of the alternative frequency weightings ( $W_{\mathrm{hf}}$ and $\left.W_{\mathrm{hT}}\right)$ is small above $60 \mathrm{~Hz}$.

The root-sum-of-squares (also called "vibration total value") of the rms acceleration frequency weighted according to $W_{\mathrm{h}}, W_{\mathrm{h}-\mathrm{bl}}, W_{\mathrm{hf}}$, or $W_{\mathrm{hT}}\left[a_{\mathrm{hv}}\left(W_{\mathrm{hi}}\right)\right]$ for the $x$-, $y$ - and $z$-axes was calculated:

$$
a_{h v}\left(W_{h i}\right)=\sqrt{a_{h x\left(W_{h i}\right)}^{2}+a_{h y\left(W_{h i}\right)}^{2}+a_{h z\left(W_{h i}\right)}^{2}} \quad\left(m s^{-2} r m s\right)
$$

The results of tool rms acceleration measurements with the four alternative frequency weightings are reported in a previous study (5).

Questionnaire data, interviews of employees and employers, and company records were used to estimate daily (hours) and lifetime (years) duration of tool usage. Moreover, to evaluate daily exposure duration to vibration, supervisors made direct observation of exposure patterns at the workplace over an entire week period. They used a stopwatch method and recorded the contact time the hands of the operators were actually exposed to the vibration from the tools.

Daily vibration exposure was evaluated according to international standard ISO 5349-1 (2) and the European Directive on mechanical vibration (14), and expressed in terms of 8-hour energy-equivalent frequency-weighted rms acceleration magnitude $\left[A(8) W_{\mathrm{hi}}\right]$ :

$$
A(8) W_{h i}=\sqrt{\frac{1}{T_{0}} \sum_{i=1}^{n}\left(a_{h v i}\left(W_{h i}\right)\right)^{2} T_{i}} \quad\left(m s^{-2} r m s\right)
$$

where $a_{\text {hvi }}\left(W_{\text {hi }}\right)$ is the vibration total value (frequency weighted with $W_{\mathrm{h}}, W_{\mathrm{h}-\mathrm{bl}}, W_{\mathrm{hf}}$, or $W_{\mathrm{hT}}$ ) for tool $i$ in $\mathrm{ms}^{-2}$ rms, $T_{i}$ is the daily duration of exposure to tool $i$ in hours, and $T_{0}$ is the reference duration of $8 \mathrm{~h}$.

\section{Ergonomic risk factors}

Physical workload on the hands and forearms was investigated by means of five questions concerning twisting, forceful or repetitive movements, uncomfortable hand positions/grips, and heavy demands on precision (4). Physical load in a typical working day was graded by rating the frequency of adverse movements and awkward postures on a 4-point response scale ["never" (score 0), "1-4 times" (score 1), "5-20 times" (score 2), and ">20 times" (score 3)]. Scores of physical demand were added up for each subject and, in the entire sample, the total score of hand/forearm physical load was categorized into quartiles, which were assumed to correspond to four grades of increasing physical load: score $0-3=$ no or 


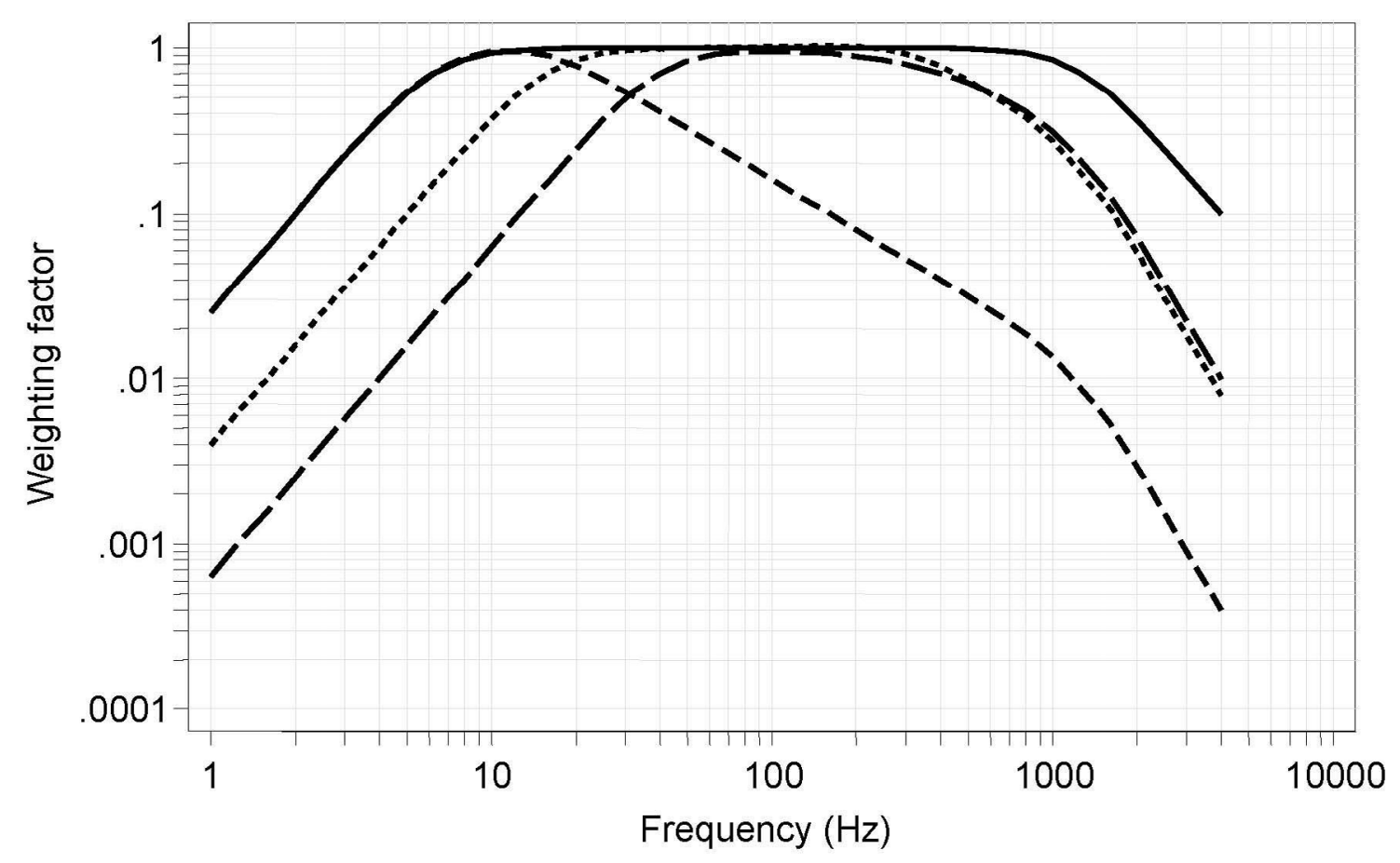

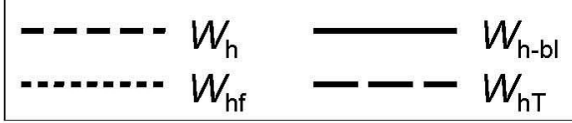

Figure 1. Comparison of frequency weighting functions for hand-transmitted vibration. [ $W_{\mathrm{h}}=$ frequency weighting as defined in ISO $5349-1: 2001$ (2); $W_{\mathrm{h}-\mathrm{bl}}=$ the band-limiting component of $W_{\mathrm{h}}(10) ; W_{\mathrm{hf}}=\mathrm{a}$ frequency weighting based on finger vibration power absorption (12); $W_{\mathrm{hT}}=\mathrm{a}$ frequency weighting based on a Japanese study of vibration-induced white finger (VWF) prevalence (13).

mild load grade, score 4-6=moderate load grade, score 7-9=medium load grade, score 10-15=hard load grade.

\section{Data analysis}

The statistical analysis of data was performed with the Stata software, version 13.1 (Stata Corp, State College, TX, USA, 2013).

Continuous variables were summarized with the median as a measure of central tendency and quartiles as measures of dispersion. Comparisons between unpaired data and correlations between paired observations were tested by means of non-parametric statistics. P-values were adjusted for multiple comparisons.

Prevalence and cumulative incidence were calculated according to traditional epidemiological methods.

The relations of neurosensory and work ability (binary or continuous) outcomes to alternative measures of vibration exposure were assessed by means of the generalized estimating equations (GEE) method in order to account for the within-subject dependency of the observations over time (15). Odds ratios (OR) or linear regression coefficients and robust $95 \%$ confidence intervals $(95 \% \mathrm{CI})$, adjusted by potential confounders, were estimated from the GEE models using logit or identity link functions, respectively.

The Quasi-likelihood Information Criterion (QIC), a modification of the Akaike's Information Criterion (AIC), was used to select the best working correlation structure in GEE analyses and to compare the fit of GEE longitudinal models including alternative measures of daily vibration exposure (16). In this study, an autoregressive correlation structure was specified for parameter estimation in GEE analyses since the QIC statistic for this structure had smaller values than those obtained with different working correlations (eg, exchangeable or unstructured structures). The models with the smallest QIC values were also chosen as the best-fitting models for the relation between outcomes and vibration exposure. To aid comparison, a $\Delta \mathrm{QIC}$ was calculated as the difference between the QIC value for a specific exposure model and the model including $A(8)$ calculated with frequency weighting $W_{\mathrm{h}}$ (ie, the ISO weighting method). By analogy, with the strength of evi- 
Table 1. Characteristics of the controls and the workers exposed to hand-transmitted vibration (HTV) at the cross-sectional survey. $[A(8)$ is the 8-hour energy-equivalent acceleration magnitude, calculated by weighting the tool root mean square (rms) acceleration magnitudes according to the four candidate frequency weightings $\left(W_{h}, W_{h-b l}, W_{h f}, W_{h T}\right)$ displayed in figure 1.]

\begin{tabular}{|c|c|c|c|c|c|c|c|c|}
\hline & \multirow{2}{*}{\multicolumn{2}{|c|}{$\begin{array}{l}\text { Controls } \\
(\mathrm{N}=138)\end{array}$}} & \multicolumn{6}{|c|}{ HTV exposed workers } \\
\hline & & & \multicolumn{2}{|c|}{ Forestry workers $(\mathrm{N}=215)$} & \multicolumn{2}{|c|}{ Stone workers $(\mathrm{N}=34)$} & \multicolumn{2}{|c|}{ Total $(\mathrm{N}=249)$} \\
\hline & Median & Quartiles & Median & Quartiles & Median & Quartiles & Median & Quartiles \\
\hline Age (years) & 38.8 & $34.1-45.9$ & 42.8 & $34.6-48.2$ & 37.2 & $30.9-43.2$ & 42.1 & $34.0-47.9$ \\
\hline Body mass index $\left(\mathrm{kg} / \mathrm{m}^{2}\right)$ & 24.5 & $23.0-27.2$ & 25.5 & $23.2-27.4$ & 25.6 & $23.5-26.8$ & 25.5 & $23.2-27.1$ \\
\hline Duration of exposure (years) & & & 15 & $6-21$ & 17 & $11-23$ & 15 & $8-21$ \\
\hline Daily HTV exposure (minutes) & . & . & 114 & $72-180$ & 373 & $335-413^{a}$ & 126 & $72-194$ \\
\hline$A(8) W_{\mathrm{h}}\left(\mathrm{ms}^{-2} \mathrm{rms}\right)$ & . & . & 3.5 & $2.5-4.8$ & 6.7 & $5.4-15.8^{a}$ & 3.8 & $2.8-5.4$ \\
\hline$A(8) W_{\mathrm{h}-\mathrm{bl}}\left(\mathrm{ms}^{-2} \mathrm{rms}\right)$ & . & . & 18.9 & $13.2-27.9$ & 94.2 & $79.6-193$ a & 20.6 & $14.3-34.6$ \\
\hline$A(8) W_{\mathrm{hf}}\left(\mathrm{ms}^{-2} \mathrm{rms}\right)$ & . & . & 17.9 & $12.9-27.3$ & 78.2 & $66.1-160^{a}$ & 19.8 & $13.7-32.3$ \\
\hline$A(8) W_{\mathrm{hT}}\left(\mathrm{ms}^{-2} \mathrm{rms}\right)$ & . & & 16.3 & $11.8-24.6$ & 72.6 & $61.3-148{ }^{a}$ & 18.0 & $12.3-30.0$ \\
\hline
\end{tabular}

a Mann-Whitney test (forestry versus stone workers) $\mathrm{P}<0.0001$

dence rules suggested for the AIC method $(16,17)$, the following guidelines for selecting the best-fitting model were adopted: $\Delta \mathrm{QIC} \leq 2$ suggests no difference in the fit between models; $4 \leq \Delta \mathrm{QIC} \leq 7$ tends to give support for the model with the smaller QIC; $\Delta$ QIC $>10$ means that the model with the smaller QIC provides a substantially better fit to the data.

\section{Results}

At the cross-sectional survey, the study groups were comparable for individual characteristics (table 1). Vibration exposure in terms of daily duration and $A(8)$ $W_{\text {hi }}$ (ie, weighted with the four alternative frequency weightings of acceleration magnitude) was greater among the stone workers than forestry operators, although duration of exposure (years) was similar in the two groups. Frequency spectra from the hand-held tools used by the HTV-exposed workers (5), and the results from table 1 show that the stone workers were more exposed to high frequency vibration than the forestry workers.

\section{Neurosensory disorders and self-reported work ability}

The prevalence and cumulative incidence of peripheral neurosensory disorders and reduced work ability were significantly greater among the HTV-exposed workers than the controls (table 2). The cumulative incidence of finger numbness was $13.2 \%(\mathrm{~N}=24)$ and $5.6 \%(\mathrm{~N}=7)$ among the HTV-exposed workers and the controls, respectively, $(\mathrm{P}<0.05)$. The incidence of numbness was $16.5 \%(\mathrm{~N}=21)$ and $6.7 \%(\mathrm{~N}=6)$, respectively, among the HTV workers and the controls who participated in three follow-ups, $6.9 \%(\mathrm{~N}=2)$ and $5.9 \%(\mathrm{~N}=1)$ among those with two follow-ups, and $3.8 \%(\mathrm{~N}=1)$ and $0 \%(\mathrm{~N}=0)$ among those with only one follow-up.
The stone workers more frequently reported the occurrence of neurosensory outcomes and decline in work ability than the forestry workers. According to the case definition established in this study, of the 43 HTV-exposed workers with VWF at baseline (5), 25 $(58 \%)$ were also affected with finger numbness, while $18(42 \%)$ did not reported this symptom. Over the follow-up period, the workers with VWF showed an increased, although not significant, risk for finger numbness when compared with those with no vascular symptoms (adjusted OR 1.32, 95\% CI 0.90-1.95, $\mathrm{P}=0.15$ ).

At baseline, quantitative sensory testing showed that grip strength, manipulative dexterity, and touch sensation were more deteriorated among the HTV-exposed workers than the controls (table 3). The stone workers showed significantly higher touch sensation thresholds in digits 2 and 5 of both hands than the forestry operators $(\mathrm{P}<0.001)$.

Among the HTV-exposed workers, the symptom of numbness was positively correlated with monofilament thresholds $(0.005<\mathrm{P}<0.05)$, and inversely associated with grip strength and manual dexterity $(\mathrm{P}<0.01)$.

Among the controls, no significant associations were observed between the symptom of numbness and the output of quantitative sensory testing (grip strength, manual dexterity, touch sensation), $(\mathrm{P}=0.46-0.94)$.

Among the HTV-exposed workers, finger numbness and cutaneous sensation thresholds were positively associated with and manual dexterity was inversely related to interference with work activities and limited work performance in the previous 12 months and to reduced work output in the last 7 days $(0.001<\mathrm{P}<0.05)$. Symptoms and signs of CTS was associated with interference with work activities solely $(\mathrm{P}<0.001)$.

Among the controls, finger numbness was related to interference with work activities $(\mathrm{P}<0.01)$. No other associations were observed between symptoms of neurosensory disorders and reduced work ability. 
Table 2. Prevalence at baseline and cumulative incidence of neurosensory symptoms and reduced work ability in the controls and the workers exposed to hand-transmitted vibration (HTV). CTS is carpal tunnel syndrome.

\begin{tabular}{|c|c|c|c|c|c|c|c|c|}
\hline & \multirow{2}{*}{\multicolumn{2}{|c|}{ Controls ( $N=138)$}} & \multicolumn{6}{|c|}{ HTV-exposed workers } \\
\hline & & & \multicolumn{2}{|c|}{$\begin{array}{l}\text { Forestry workers } \\
\quad(N=215)\end{array}$} & \multicolumn{2}{|c|}{$\begin{array}{l}\text { Stone workers } \\
(N=34)\end{array}$} & \multicolumn{2}{|c|}{$\begin{array}{c}\text { Total } \\
(\mathrm{N}=249)\end{array}$} \\
\hline & $\mathrm{N}$ & $\%$ & $\mathrm{~N}$ & $\%$ & $\mathrm{~N}$ & $\%$ & $\mathrm{~N}$ & $\%$ \\
\hline \multicolumn{9}{|l|}{ Tingling } \\
\hline Prevalence & 20 & 14.5 & 91 & $42.3^{\mathrm{a}}$ & 19 & $55.9^{b}$ & 110 & $44.2^{\mathrm{c}}$ \\
\hline Cumulative incidence & 20 & 21.2 & 40 & 32.3 & 6 & 40.0 & 46 & $33.1^{d}$ \\
\hline \multicolumn{9}{|l|}{ Numbness } \\
\hline Prevalence & 12 & 8.7 & 56 & $26.0^{\mathrm{e}}$ & 11 & $32.4^{\mathrm{f}}$ & 67 & $26.9^{\mathrm{c}}$ \\
\hline Cumulative incidence & 7 & 5.6 & 20 & 12.6 & 4 & 17.4 & 24 & $13.2^{d}$ \\
\hline \multicolumn{9}{|l|}{ Suspected CTS } \\
\hline Prevalence & 2 & 1.5 & 19 & $8.8^{\mathrm{g}}$ & 3 & 8.8 & 22 & $8.8^{\mathrm{d}}$ \\
\hline Cumulative incidence & 1 & 0.7 & 5 & 2.6 & 7 & $22.6^{\mathrm{h}, \mathrm{i}}$ & 12 & $5.3^{d}$ \\
\hline \multicolumn{9}{|c|}{ Interference with work activities in the last 12 months } \\
\hline Prevalence & 2 & 1.5 & 16 & $7.4^{\mathrm{g}}$ & 8 & $23.5^{\mathrm{h}, \mathrm{i}}$ & 24 & $9.6^{c}$ \\
\hline Cumulative incidence & 16 & 11.8 & 53 & $26.6^{\mathrm{e}}$ & 7 & 26.9 & 60 & $26.7^{\mathrm{c}}$ \\
\hline \multicolumn{9}{|c|}{ Limited work performance in the last 12 months } \\
\hline Prevalence & 3 & 2.2 & 15 & 7.0 & 9 & $26.5^{\mathrm{h}, \mathrm{i}}$ & 24 & $9.6^{i}$ \\
\hline Cumulative incidence & 0 & 0 & 8 & 4.0 & 1 & 4.0 & 9 & $4.0^{d}$ \\
\hline \multicolumn{9}{|c|}{ Reduced work output in the previous 7 days } \\
\hline Prevalence & 1 & 0.7 & 5 & 2.3 & 2 & 5.9 & 7 & 2.8 \\
\hline Cumulative incidence & 1 & 0.7 & 6 & 2.9 & 5 & $15.6^{\mathrm{h}, \mathrm{i}}$ & 11 & $4.5^{\mathrm{d}}$ \\
\hline
\end{tabular}

a $P<0.001$ multicomparisons (adjusted P-values): forestry workers versus controls.

b $P<0.001$ stone workers versus controls.

c $P<0.001$ ( $\chi^{2}$ or Fisher's exact test): HTV workers versus controls.

d $P<0.05$ ( $\chi^{2}$ or Fisher's exact test): HTV workers versus controls.

e $P<0.01$ multicomparisons (adjusted P-values): forestry workers versus controls.

f $P<0.05$ stone workers versus controls.

g $\mathrm{P}<0.05$ multicomparisons (adjusted $\mathrm{P}$-values): forestry workers versus controls.

h $P<0.01$ stone workers versus controls.

i $P<0.01$ stone workers versus forestry workers.

i $P<0.01$ ( $\chi^{2}$ or Fisher's exact test): HTV workers versus controls.

Table 3. Grip strength (N), manipulative dexterity (Purdue pegboard scores), and touch sensations [Semmes-Weinstein (S-W) monofilament thresholds] in the controls and the workers exposed to hand-transmitted vibration (HTV) at the cross-sectional survey.

\begin{tabular}{|c|c|c|c|c|c|c|c|c|}
\hline \multirow[t]{3}{*}{ Quantitative sensory tests } & \multirow{2}{*}{\multicolumn{2}{|c|}{ Controls $(\mathrm{N}=138)$}} & \multicolumn{6}{|c|}{ HTV-exposed workers } \\
\hline & & & \multicolumn{2}{|c|}{$\begin{array}{l}\text { Forestry workers } \\
\quad(\mathrm{N}=215)\end{array}$} & \multicolumn{2}{|c|}{$\begin{array}{l}\text { Stone workers } \\
\quad(N=34)\end{array}$} & \multicolumn{2}{|c|}{$\begin{array}{c}\text { Total } \\
(\mathrm{N}=249)\end{array}$} \\
\hline & Median & Quartiles & Median & Quartiles & Median & Quartiles & Median & Quartiles \\
\hline \multicolumn{9}{|l|}{ Grip strength (N) } \\
\hline Dominant hand & 549 & $490-621$ & 454 & $356-562$ a & 490 & $434-572^{\text {b }}$ & 457 & $382-562^{c}$ \\
\hline Non-dominant hand & 532 & $464-588$ & 451 & $339-562$ a & 506 & $431-542$ & 464 & $343-555^{c}$ \\
\hline \multicolumn{9}{|l|}{ Purdue pegboard score (pegs) } \\
\hline Dominant hand & 14 & $13-16$ & 13 & $11-14^{d}$ & 13 & $11-14 \mathrm{e}$ & 13 & $12-14^{c}$ \\
\hline Non-dominant hand & 13 & $12-15$ & 13 & $12-14^{d}$ & 12 & $12-13^{b}$ & 13 & $12-14^{c}$ \\
\hline Both hands & 11 & $10-12$ & 10 & $9-11^{f}$ & 10 & $9-11^{\mathrm{b}}$ & 10 & $9-11^{c}$ \\
\hline \multicolumn{9}{|c|}{ S-W monofilament thresholds (g) } \\
\hline $2^{\text {nd }}$ right finger & 0.407 & $0.068-0.407$ & 0.407 & $0.068-0.407$ & 2.041 & $0.407-2.041 \mathrm{e}, \mathrm{g}$ & 0.407 & $0.068-0.407^{\mathrm{h}}$ \\
\hline $5^{\text {th }}$ right finger & 0.068 & $0.068-0.407$ & 0.407 & $0.068-0.407^{\dagger}$ & 2.041 & $0.407-2.041^{e, g}$ & 0.407 & $0.407-0.407^{c}$ \\
\hline $2^{\text {nd }}$ left finger & 0.068 & $0.068-0.407$ & 0.068 & $0.068-0.407$ & 2.041 & $0.407-2.041^{e, g}$ & 0.407 & $0.068-0.407^{\mathrm{h}}$ \\
\hline $5^{\text {th }}$ left finger & 0.068 & $0.068-0.407$ & 0.407 & $0.068-0.407^{f}$ & 2.041 & $0.407-2.041^{e, g}$ & 0.407 & $0.068-0.407^{\mathrm{h}}$ \\
\hline
\end{tabular}

a $\mathrm{P}<0.001$ Kruskal-Wallis test (adjusted P-values for multiple comparisons): forestry workers versus controls.

b $\mathrm{P}<0.01$ Kruskal-Wallis test (adjusted $\mathrm{P}$-values for multiple comparisons): stone workers versus controls.

c $P<0.001$ Mann-Whitney test (HTV workers versus controls).

d $\mathrm{P}<0.05$ Kruskal-Wallis test (adjusted $\mathrm{P}$-values for multiple comparisons): forestry workers versus controls.

e $P<0.001$ Kruskal-Wallis test (adjusted $P$-values for multiple comparisons): stone workers versus controls.

${ }^{f} \mathrm{P}<0.01$ Kruskal-Wallis test (adjusted P-values for multiple comparisons): forestry workers versus controls.

g $P<0.001$ Kruskal-Wallis test (adjusted $P$-values for multiple comparisons): stone workers versus forestry workers.

n $\mathrm{P}<0.02$ Mann-Whitney test (HTV workers versus controls). 
Table 4. Relations of neurosensory symptoms and reduced work ability to alternative measures of daily vibration exposure $[A(8)]$ and duration of exposure in the vibration exposed workers. $A(8)$ was calculated by weighting the tool root mean square (rms) acceleration magnitudes according to the four candidate frequency weightings $\left(W_{\mathrm{h}}, W_{\mathrm{h}-\mathrm{bl}}, W_{\mathrm{hf}}, W_{\mathrm{hT}}\right)$ displayed in figure 1. Odds ratios (OR) (adjusted by age at entry, body mass index, smoking and drinking habits, and hand/forearm physical load) and robust $95 \%$ confidence intervals $(95 \% \mathrm{Cl})$ were estimated by means of the generalized estimating equations method for repeated measures over time. The Quasi-likelihood Information Criterion (QIC) is used to compare models. QIC difference $(\Delta)$ is calculated as the difference between the QIC value for a specific exposure model and the $A(8) W_{\mathrm{h}}$ model. The changes in the $0 \mathrm{R}$ for a change of $1 \mathrm{~ms}^{-2} \mathrm{rms}$ for $A(8) W_{\mathrm{h}}$ and $10 \mathrm{~ms}^{-2} \mathrm{rms}$ for $A(8)$ $W_{\mathrm{h}-\mathrm{b}}, A(8) W_{\mathrm{hf}}$, and $A(8) W_{\mathrm{hT}}$ are shown. [CTS=carpal tunnel syndrome.]

\begin{tabular}{|c|c|c|c|c|c|c|c|c|c|c|c|c|}
\hline \multirow[t]{2}{*}{$\begin{array}{l}\text { Alternative measures of } \\
\text { vibration exposure }\end{array}$} & \multicolumn{2}{|c|}{ Tingling } & \multicolumn{2}{|c|}{ Numbness } & \multicolumn{2}{|c|}{$\begin{array}{l}\text { Suspected } \\
\text { CTS }\end{array}$} & \multicolumn{2}{|c|}{$\begin{array}{l}\text { Interference with } \\
\text { work activities }\end{array}$} & \multicolumn{2}{|c|}{$\begin{array}{l}\text { Limited work } \\
\text { performance }\end{array}$} & \multicolumn{2}{|c|}{$\begin{array}{c}\text { Reduced } \\
\text { work output }\end{array}$} \\
\hline & OR & & $\mathrm{OR}$ & & & & $\mathrm{OR}$ & & $\mathrm{OR}$ & & $\mathrm{OR}$ & \\
\hline & 16 & $\begin{array}{l}0.99-1 \\
1.04-1 \\
77(0)\end{array}$ & & $66(0)$ & & $00(0)$ & & $9(0)$ & & $37(0)$ & $\begin{array}{l}15 \\
06 \\
2\end{array}$ & $5(0)$ \\
\hline $\begin{array}{l}\text { (8) } W_{\text {h-bl }}\left(\times 10 \mathrm{~ms}^{-2} \mathrm{rms}\right) \\
\text { xposure duration (year) } \\
\text { IC }(\Delta)\end{array}$ & $\begin{array}{r}1.06 \\
1.08 \\
16\end{array}$ & $\begin{array}{l}0.99-1.14 \\
1.04-1.11^{\mathrm{c}} \\
75(2)\end{array}$ & $\begin{array}{r}1.08 \\
1.04 \\
14\end{array}$ & 80 (14) & $\begin{array}{r}1.09 \\
1.03 \\
51\end{array}$ & $4(14)$ & $\begin{array}{l}1.11 \\
1.04\end{array}$ & $8(1)$ & $\begin{array}{l}1.17 \\
1.04\end{array}$ & $0(3)$ & $\begin{array}{r}1.10 \\
1.06 \\
2\end{array}$ & 7 (2) \\
\hline $\begin{array}{l}A(8) W_{\mathrm{hf}}\left(\times 10 \mathrm{~ms}^{-2} \mathrm{rms}\right) \\
\text { Exposure duration (year) } \\
\text { QIC }(\Delta)\end{array}$ & $\begin{array}{r}1.07 \\
1.08 \\
16\end{array}$ & $\begin{array}{l}0.99-1.16 \\
1.04-1.12^{c} \\
75(2)\end{array}$ & $\begin{array}{l}1.10 \\
1.04\end{array}$ & $\begin{array}{l}1.01-1 \\
76(10)\end{array}$ & & $\begin{array}{l}1.03-1.18^{b} \\
0.99-1.08 \\
5(15)\end{array}$ & $\begin{array}{l}1.14 \\
1.04\end{array}$ & $\begin{array}{l}1.04-1.24 \mathrm{~b} \\
0.99-1.10 \\
6(3)\end{array}$ & & $\begin{array}{l}1.12-1.29 \mathrm{c} \\
1.00-1.09 \mathrm{a}\end{array}$ & $\begin{array}{r}1.13 \\
1.06 \\
2\end{array}$ & $7(2)$ \\
\hline $\begin{array}{l}A(8) W_{\mathrm{hT}}\left(\times 10 \mathrm{~ms}^{-2} \mathrm{rms}\right) \\
\text { Exposure duration (year) } \\
\text { QIC }(\Delta)\end{array}$ & $\begin{array}{r}1.08 \\
1.08 \\
16\end{array}$ & $\begin{array}{l}1.04-1 . \\
75(2)\end{array}$ & $\begin{array}{l}1.11 \\
1.04\end{array}$ & $\begin{array}{l}1.01-1.0 \\
77(11)\end{array}$ & $\begin{array}{r}1.11 \\
1.03 \\
51\end{array}$ & $\begin{array}{l}0.99-1 \\
5(15)\end{array}$ & $\begin{array}{r}1.15 \\
1.04 \\
5\end{array}$ & $\begin{array}{l}1.05-1.27^{b} \\
0.99-1.10 \\
6(3)\end{array}$ & $\begin{array}{r}1.22 \\
1.04 \\
4 S^{\circ}\end{array}$ & $\begin{array}{l}1.00-1 \\
0(3)\end{array}$ & $\begin{array}{r}1.14 \\
1.06 \\
2\end{array}$ & $\begin{array}{l}1.00- \\
7(2)\end{array}$ \\
\hline
\end{tabular}

a $P<0.05$ Wald test

b $P<0.01$ Wald test.

c $\mathrm{P}<0.001$ Wald test.

Table 5. Relation of cutaneous sensation (Semmes-Weinstein monofilament thresholds) to alternative measures of daily vibration exposure $[A(8)]$ in the vibration-exposed workers. $A(8)$ was calculated by weighting the tool root mean square (rms) acceleration magnitudes according to the four candidate frequency weightings $\left(W_{h}, W_{h-b l}, W_{h f}, W_{h T}\right)$ displayed in Figure 1 . The regression coefficients (adjusted by age at entry, body mass index, smoking and drinking habits, hand/forearm physical load, and duration of exposure) and robust $95 \%$ confidence intervals $(95 \% \mathrm{Cl})$ were estimated by means of the generalized estimating equations method for repeated measures over time. QIC is the Quasi-likelihood Information Criterion for the comparison between models. QIC difference $(\Delta)$ is calculated as the difference between the QIC value for a specific exposure model and the $A(8) W_{\mathrm{h}}$ model. The changes in monofilament thresholds for a change of 1 $\mathrm{ms}^{2}$ rms for $A(8) W_{\mathrm{h}}$ and $10 \mathrm{~ms}^{2} \mathrm{rms}$ for $A(8) W_{\mathrm{h}-\mathrm{bl}}, A(8) W_{\mathrm{hf}}$, and $A(8) W_{\mathrm{hT}}$ are shown.

\begin{tabular}{|c|c|c|c|c|c|c|c|c|}
\hline \multirow{3}{*}{$\begin{array}{l}\text { Alternative measures of daily } \\
\text { vibration exposure }\end{array}$} & \multicolumn{8}{|c|}{ Semmes-Weinstein monofilament thresholds (g) } \\
\hline & \multicolumn{2}{|c|}{$2^{\text {nd }}$ right finger } & \multicolumn{2}{|c|}{$5^{\text {th }}$ right finger } & \multicolumn{2}{|c|}{$2^{\text {nd }}$ left finger } & \multicolumn{2}{|c|}{$5^{\text {th }}$ left finger } \\
\hline & Coefficient & $95 \% \mathrm{Cl}$ & Coefficient & $95 \% \mathrm{Cl}$ & Coefficient & $95 \% \mathrm{Cl}$ & Coefficient & $95 \% \mathrm{Cl}$ \\
\hline$A(8) W_{\mathrm{h}}\left(\times 1 \mathrm{~ms}^{-2} \mathrm{rms}\right)$ & 0.054 & $0.025-0.083^{b}$ & 0.040 & $0.016-0.063^{c}$ & 0.042 & $0.013-0.071^{c}$ & 0.042 & $0.020-0.064^{b}$ \\
\hline QIC $(\Delta)$ & \multicolumn{2}{|c|}{$213(0)$} & \multicolumn{2}{|c|}{$146(0)$} & \multicolumn{2}{|c|}{$181(0)$} & \multicolumn{2}{|c|}{$160(0)$} \\
\hline$A(8) W_{\text {h-bl }}\left(\times 10 \mathrm{~ms}^{-2} \mathrm{rms}\right)$ & 0.060 & $0.036-0.085^{b}$ & 0.045 & $0.025-0.065^{b}$ & 0.049 & $0.025-0.073^{b}$ & 0.049 & $0.029-0.069 \mathrm{~b}$ \\
\hline QIC $(\Delta)$ & \multicolumn{2}{|c|}{$197(16)$} & \multicolumn{2}{|c|}{$140(6)$} & \multicolumn{2}{|c|}{$167(14)$} & \multicolumn{2}{|c|}{$149(11)$} \\
\hline$A(8) W_{\mathrm{hf}}\left(\times 10 \mathrm{~ms}^{-2} \mathrm{rms}\right)$ & 0.072 & $0.043-0.102^{b}$ & 0.054 & $0.029-0.078 \mathrm{~b}$ & 0.059 & $0.030-0.088^{b}$ & 0.058 & $0.035-0.082^{b}$ \\
\hline $\mathrm{QIC}(\Delta)$ & \multicolumn{2}{|c|}{$199(14)$} & \multicolumn{2}{|c|}{$141(5)$} & \multicolumn{2}{|c|}{$169(12)$} & \multicolumn{2}{|c|}{$151(9)$} \\
\hline$A(8) W_{\mathrm{hT}}\left(\times 10 \mathrm{~ms}^{-2} \mathrm{rms}\right)$ & 0.078 & $0.046-0.110^{b}$ & 0.058 & $0.032-0.085^{b}$ & 0.063 & $0.032-0.095^{b}$ & 0.063 & $0.038-0.088^{b}$ \\
\hline QIC $(\Delta)$ & \multicolumn{2}{|c|}{$199(14)$} & \multicolumn{2}{|c|}{$141(5)$} & \multicolumn{2}{|c|}{$169(12)$} & \multicolumn{2}{|c|}{$151(9)$} \\
\hline
\end{tabular}

a $P<0.001$.

${ }^{\mathrm{b}} \mathrm{P}<0.01$.

Neurosensory outcomes, self-reported work ability, and alternative measures of vibration exposure

After excluding the controls from data analysis and adjusting for confounding factors, the GEE logistic analysis showed that the four alternative measures of daily vibration exposure and the duration of exposure (years) were significantly associated with the occurrence of most neurosensory and work ability outcomes among the HTV-exposed workers (table 4). The QIC statistic revealed that the model including the ISO frequency weighting $\left(A(8) W_{\mathrm{h}}\right)$ fitted the data for the occurrence of numbness and suspected CTS better than the other models constructed with alternative frequency weightings ( $\triangle$ QIC 10-15). The excess risk for numbness or CTS varied from $8-13 \%$ per unit increase in daily vibration 
Table 6. Observed and predicted occurrence of finger numbness among the vibration-exposed workers by job title and alternative measures of daily vibration exposure in terms of 8-hour energyequivalent acceleration magnitude $[A(8)]$. $A(8)$ was calculated by weighting the tool root mean square (rms) acceleration magnitudes according to the four candidate frequency weightings $\left(W_{\mathrm{h}}\right.$, $\left.W_{\mathrm{h}-\mathrm{b}}, W_{\mathrm{hf}}, W_{\mathrm{hT}}\right)$ displayed in figure 1 . The predicted occurrence of numbness is estimated by the generalized estimating equations method (see models in table 4).

\begin{tabular}{|c|c|c|c|c|c|}
\hline \multirow[t]{3}{*}{ Job title } & \multicolumn{5}{|c|}{ Finger numbness occurrence } \\
\hline & \multirow{2}{*}{$\begin{array}{c}\text { Observed } \\
(\%)\end{array}$} & \multicolumn{4}{|c|}{ Predicted $(\%)$} \\
\hline & & $A(8) W_{\mathrm{h}}$ & $A(8) W_{\mathrm{h}-b l}$ & $A(8) W_{\text {hf }}$ & $A(8) W_{\mathrm{hT}}$ \\
\hline Forestry workers & 35.3 & 31.1 & 31.5 & 31.5 & 31.5 \\
\hline Stone workers & 44.1 & 38.3 & 38.3 & 38.3 & 38.3 \\
\hline All workers & 36.5 & 32.1 & 32.4 & 32.4 & 32.4 \\
\hline
\end{tabular}

exposure $\left[1 \mathrm{~ms}^{-2} \mathrm{rms}\right.$ for $A(8) W_{\mathrm{h}}, 10 \mathrm{~ms}^{-2} \mathrm{rms}$ for $A(8)$ $W_{\mathrm{h}-\mathrm{bl}}, A(8) W_{\mathrm{hf}}$ or $\left.A(8) W_{\mathrm{hT}}\right]$. No differences in the fit to tingling and self-reported work ability were observed between the various models ( $\triangle$ QIC 1-3).

There was no difference between the alternative measures of daily vibration exposure for the assessment of the changes over time in grip strength and manipulative dexterity ( $\triangle$ QIC $1-2)$ (results not shown).

All alternative measures of daily vibration exposure were significantly related to the deterioration of touch sensation (ie, increase in Semmes-Weinstein's monofilament thresholds) among the HTV-exposed workers (table 5). The models including $A(8) W_{\mathrm{h}-\mathrm{bl}}, A(8) W_{\mathrm{hf}}$ or $A(8) W_{\mathrm{hT}}$ provided a better fit to the measures of cutaneous sensation than the ISO model $\left(A(8) W_{\mathrm{h}}\right),(\Delta \mathrm{QIC}$ 5-16).

Since persistent numbness in the fingers and hands is considered a typical symptom of vibration-induced neurological disorders $(8,18)$, the models in table 4 were used to compare the observed occurrence of numbness in the HTV-exposed workers with that predicted by the alternative measures of daily vibration exposure (table 6). Although the magnitude of the QIC statistic suggested a preference for the ISO model (table 4), the four measures of vibration exposure gave rise to nearly identical estimates for the prediction of numbness in the total HTV-exposed sample, as well as in the forestry operators and the stone workers separately. Overall, the predicted estimates tended to underestimate about $4 \%$ of the observed occurrence of finger numbness among the HTV-exposed workers.

In addition to vibration exposure, multivariable data analysis showed that age and years of exposure, but not body mass index, smoking or drinking habits, were significant predictors of most neurosensory and work ability outcomes (table 7). In the entire study population, hard physical load on the hand and forearm was significantly associated with the occurrence of neurosensory symptoms, interference with work activities and lim- ited work performance. When $A(8) W_{\mathrm{h}}$ was treated as a tertile-based design variable, a clear exposure-response relationship was observed between daily vibration exposure and neurosensory and work ability outcomes, mainly in the HTV-exposed workers exposed to $A(8)$ $W_{\mathrm{h}}>3.0 \mathrm{~ms}^{-2} \mathrm{rms}$, a figure consistent with the action value for HTV $\left(2.5 \mathrm{~ms}^{-2} \mathrm{rms}\right)$ established by the EU Directive on mechanical vibration (14). Similar results (not shown) were found when daily vibration exposure was expressed in terms of $A(8) W_{\mathrm{h}-\mathrm{bl}}, A(8) W_{\mathrm{hf}}$ or $A(8) W_{\mathrm{hT}}$.

There were no significant interactions between covariates and measures of vibration exposure (categorical or continuous) when appropriate product terms were included in the regression models.

\section{Discussion}

\section{Exposure-response relationship for vibration-induced sensory disorders}

In this prospective cohort study of HTV-exposed workers, there was evidence for significant dose-response relationships between symptoms and signs of peripheral neurosensory disorders and measures of vibration exposure expressed in terms of duration and tool rms acceleration magnitude weighted by means of alternative frequency weighting functions. Increased prevalence or excess risk for neurosensory disturbances, CTS and/or abnormal sensory testing have been reported in crosssectional studies of HTV-exposed workers carried out in several countries (19-21). Only few studies have investigated prospectively the occurrence of neurosensory disorders in HTV-exposed workers. In a recent cohort study of HTV-exposed workers employed in a Swedish engineering plant and examined at baseline and followed up after 5,10, and 16 years, survival analysis revealed a dose-response relationship between the occurrence of finger numbness and cumulative vibration exposure estimated in accordance with ISO 5349-1 (22). In the same Swedish cohort, the incidence of CTS and numbness affecting work performance was higher among the HTV-exposed workers than the control group formed by office workers, supporting the findings of the present study that showed an increased risk for neurosensory disorders and reduced work ability among the forestry and stone workers compared to the controls.

Although some clinical investigations have found that neurosensory symptoms and impairment to grip force and manual dexterity are associated with poorer quality of life among HTV-exposed patients $(23,24)$, there is a shortage of epidemiological information about the negative influence of vibration-induced neurosensory disorders on work performance. Our findings of 
Table 7. Relations of neurosensory symptoms and reduced work ability to individual- and work-related predictors in the entire study population. Odds ratios $(\mathrm{OR})$ and robust $95 \%$ confidence intervals $(95 \% \mathrm{CI})$ were estimated by means of the generalized estimating equations method for repeated measures over time. [BMI=body mass index; CTS=carpal tunnel syndrome.]

\begin{tabular}{|c|c|c|c|c|c|c|c|c|c|c|c|c|}
\hline \multirow[t]{2}{*}{ Predictors } & \multicolumn{2}{|c|}{ Tingling } & \multicolumn{2}{|c|}{ Numbness } & \multicolumn{2}{|c|}{$\begin{array}{l}\text { Suspected } \\
\text { CTS }\end{array}$} & \multicolumn{2}{|c|}{$\begin{array}{l}\text { Interference with } \\
\text { work activities }\end{array}$} & \multicolumn{2}{|c|}{$\begin{array}{l}\text { Limited work } \\
\text { performance }\end{array}$} & \multicolumn{2}{|c|}{$\begin{array}{l}\text { Reduced work } \\
\text { output }\end{array}$} \\
\hline & OR & $95 \% \mathrm{Cl}$ & $\mathrm{OR}$ & $95 \% \mathrm{Cl}$ & $\mathrm{OR}$ & $95 \% \mathrm{Cl}$ & $\mathrm{OR}$ & $95 \% \mathrm{Cl}$ & OR & $95 \% \mathrm{Cl}$ & OR & $95 \% \mathrm{Cl}$ \\
\hline Age $\left(\right.$ years $\left.\times 10^{-1}\right)$ & 1.51 & $1.29-1.77$ a & 1.34 & $1.12-1.59 \mathrm{~b}$ & 1.46 & $1.01-2.10 \mathrm{a}$ & 1.46 & $1.03-2.06^{c}$ & 2.02 & $1.43-2.85$ a & 1.30 & $0.61-2.76$ \\
\hline $\mathrm{BMI}\left(\mathrm{kg} / \mathrm{m}^{2}\right)$ & 1.00 & $0.96-1.04$ & 1.04 & $0.98-1.09$ & 1.07 & $0.97-1.18$ & 0.99 & $0.91-1.07$ & 0.96 & $0.88-1.04$ & 0.97 & $0.82-1.14$ \\
\hline Smoking (yes vs no) & 0.98 & $0.75-1.27$ & 0.85 & $0.51-1.41$ & 1.00 & $0.45-2.19$ & 1.03 & $0.61-1.74$ & 1.07 & $0.63-1.82$ & 0.62 & $0.20-1.88$ \\
\hline Drinking (yes vs no) & 1.12 & $0.77-1.62$ & 1.19 & $0.99-1.42$ & 1.45 & $0.71-2.96$ & 1.76 & $0.87-3.57$ & 1.50 & $0.76-2.99$ & 1.75 & $0.44-6.87$ \\
\hline $\begin{array}{l}\text { Duration of exposure } \\
\left(\text { years } \times 10^{-1}\right)\end{array}$ & 1.62 & $1.34-1.96^{\text {a }}$ & 1.65 & $1.19-2.30^{\mathrm{b}}$ & 1.57 & $1.11-2.22^{c}$ & 1.62 & $1.15-2.28^{b}$ & 1.32 & $0.93-1.86$ & 1.68 & $0.97-2.92$ \\
\hline \multicolumn{13}{|l|}{$A(8) W_{\mathrm{h}}{ }^{\mathrm{d}}$} \\
\hline Unexposed controls & 1.0 & & 1.0 & & 1.0 & & 1.0 & & 1.0 & & 1.0 & \\
\hline $0.7-3.0 \mathrm{~ms}^{-2} \mathrm{rms}$ & 0.95 & $0.61-1.47$ & 1.59 & $0.96-2.65$ & 4.84 & $1.17-20.1^{c}$ & 1.30 & $0.33-5.14$ & 0.83 & $0.23-2.97$ & 0.43 & $0.04-5.38$ \\
\hline $3.1-4.6 \mathrm{~ms}^{-2} \mathrm{rms}$ & 1.44 & $0.92-2.25$ & 2.82 & $1.70-4.67^{\text {a }}$ & 3.75 & $0.87-16.2$ & 3.73 & $1.02-13.6^{\text {a }}$ & 2.95 & $0.95-9.13$ & 2.69 & $0.38-18.9$ \\
\hline $4.7-19.3 \mathrm{~ms}^{-2} \mathrm{rms}$ & 1.98 & $1.26-3.10^{b}$ & 3.09 & $1.87-5.11^{\mathrm{a}}$ & 11.2 & $2.79-44.9$ a & 4.21 & $1.17-15.1^{\mathrm{a}}$ & 5.14 & $1.74-15.2^{b}$ & 5.05 & $1.00-25.4^{c}$ \\
\hline \multicolumn{13}{|c|}{ Hand/forearm physical load } \\
\hline No/mild (score 0-3) & 1.0 & & 1.0 & & 1.0 & & 1.0 & & 1.0 & & 1.0 & \\
\hline Moderate (score 4-6) & 1.94 & $1.34-2.79$ a & 1.16 & $0.75-1.79$ & 0.97 & $0.38-2.45$ & 1.22 & $0.40-3.73$ & 2.13 & $0.79-5.70$ & 0.68 & $0.18-2.66$ \\
\hline Medium (score 7-9) & 2.59 & $1.75-3.84^{\text {a }}$ & 1.22 & $0.78-1.90$ & 0.47 & $0.18-1.21$ & 1.61 & $0.56-4.64$ & 1.08 & $0.38-3.03$ & 0.20 & $0.04-1.10$ \\
\hline Hard (score 10-15) & 2.36 & $1.54-3.60^{\text {a }}$ & 1.68 & $1.05-2.69^{c}$ & 1.08 & $0.44-2.70$ & 3.02 & $1.15-2.28^{c}$ & 3.06 & $1.14-8.19^{c}$ & 0.77 & $0.26-2.30$ \\
\hline
\end{tabular}

an increased risk for reduced work ability in the HTVexposed workers may be of help for the implementation of further studies aimed at investigating the impairment to work capacity caused by long-term exposure to vibration (25). These adverse effects, however, may not be attributed only to vibration since working with vibratory tools entails also exposure to ergonomic risk factors such as hand/forearm physical overload which was associated with sensory symptoms, interference with work activities and limited work performance in this study.

It has been reported that psychosocial risk factors can be associated with an increased risk of musculoskeletal symptoms of pain, discomfort and stiffness in the neck and upper limbs (26). In the present study, the dimensions of psychosocial work environment (job demands, job control, social support) were not investigated, but there is epidemiological evidence that psychosocial risk factors are not related to the occurrence of symptoms and signs of peripheral neurosensory disorders like in CTS. This latter has been found to be predominantly associated with the use of vibratory tools and work tasks with high demands for hand force, repetitive movements or awkward postures of the hand and wrist, either separately or in combination $(27,28)$.

\section{Alternative frequency weightings of vibration for neurosensory disorders}

In accordance with the proposal of exposure-response relationship for vibration-induced disorders included in annex C of the international standard ISO 5349-1 (2), in this study, daily vibration exposure $\left[A(8) W_{\text {hi }}\right]$ and years of exposure were used to predict the occurrence of persistent numbness in the fingers and hands of the HTVexposed workers. Numbness is a hallmark symptom of vibration-induced neurosensory disorders and is used in the clinical diagnosis and staging of the severity of the neurological component of $\operatorname{HAVS}(8,18,22)$.

In a previously published study of VWF in this cohort (5), we found that measures of daily vibration exposure, which give relatively more weight to intermediate and high frequency vibration [ie, $A(8) W_{\mathrm{h}-\mathrm{bl}}, A(8)$ $W_{\mathrm{hf}}$ or $\left.A(8) W_{\mathrm{hT}}\right]$, were better predictors of the occurrence of VWF than a measure calculated with the currently recommended ISO frequency weighting $\left[A(8) W_{\mathrm{h}}\right]$. The frequency-dependence of either acute reduction in finger blood flow or chronic disorders of finger circulation caused by exposure to HTV is supported by the results of experimental and epidemiological studies of either healthy subjects or HTV-exposed workers affected with VWF (29).

The findings of the present study did not provide definite evidence of a preference for a single frequency weighting of HTV for the prediction of vibrationinduced neurosensory disorders in the HTV-exposed workers. Although the models including the four alternative frequency weightings provided the same predictions for the occurrence of persistent numbness in the HTVexposed workers, a measure of statistical fit gave more support to the ISO model $\left[A(8) W_{\mathrm{h}}\right]$. In contrast, the other candidate measures of daily vibration exposure, which provide less attenuation of vibration acceleration with 
intermediate or high frequency components $\left[A(8) W_{\mathrm{h}-\mathrm{bl}}\right.$, $A(8) W_{\mathrm{hf}}$ or $\left.A(8) W_{\mathrm{hT}}\right]$, performed better for the assessment of the deterioration of touch sensation. Thus, even though all of the four alternative frequency weightings of HTV were significant predictors of neurosensory disorders (tables 4 and 5), nevertheless data analyses were unable to differentiate between them on the basis of the results of model fitting. It should be recognized, however, that model selection in clinical or epidemiological studies should not be based merely on a fit statistic since a single best-fitting model does not always provide the most plausible interpretation of the occurrence of a disease or the underlying pathophysiological mechanisms associated with a disorder.

Although the findings of this study differ from those observed for VWF in the same cohort, they may be interpreted at the light of the results of psychophysical and neurophysiological investigations of the tactile sense in humans. The tactile sensitivity in the fingers and hands depends on the anatomical and functional integrity of four cutaneous mechanoreceptors and related afferent fibers which have fast or slow adaptation (FA or SA), and small or large receptive fields (type I or type II). The FA I units (anatomically linked to Meissner corpuscles) respond to skin motion in the frequency range $1-300 \mathrm{~Hz}$ (peak sensitivity: 20-50 Hz); the FA II units (Pacinian corpuscles) respond to vibration within a wide range of frequencies from 5-1000 Hz (peak sensitivity: 100-300 $\mathrm{Hz}$ ); the SA I units (Merkel disks) are responsible for edge/point sensitivity and form/texture perception in the frequency range $0-100 \mathrm{~Hz}$ (peak sensitivity: $3-5 \mathrm{~Hz}$ ); the SA II units (Ruffini endings) respond to skin stretching and tangential forces at low frequencies $(<8 \mathrm{~Hz}$; peak sensitivity: $0.5 \mathrm{~Hz})(30,31)$. In addition to providing tactile information, these mechanoreceptors (mainly the SA I, FA I, and FA II units) are involved in the motor control of gripping and manipulation of objects (31). Thus, neurophysiological research has shown that the cutaneous receptors responsible for tactile sense and precise motor control of the hand respond to signals with a wide range of frequencies which overlap each other. Moreover, animal experiments have demonstrated that in a rat-tail vibration model nerve damage (intraneural edema, disrupted myelinated axons) occurs at a wide range of vibration frequencies from $30-800 \mathrm{~Hz}$ (32).

As aforementioned, in this study alternative measures of daily vibration exposure constructed with four different frequency weightings of HTV predicted the same probability of occurrence of finger numbness in the exposed workers. As a result, it may be hypothesized that (over the nominal frequency range from 5.6-1400 $\mathrm{Hz}$ recommended by ISO 5349-1 (2) for the assessment of the health effects of HTV) neurosensory symptoms in HTV-exposed workers are not selectively associated with a single frequency weighting of vibration.
Experimental studies have shown that the frequencydependence of the psychophysical and neurophysiological responses to HTV is complex, non-linear, and highly dependent on other factors such as the vibration magnitude, the hand posture, the contact location and contact force, the stimulus duration, and the skin temperature (33). Since there is a big overlapping between the vibration frequencies to which the sensory endings are sensitive (31), it may be inferred that different combinations of cutaneous receptors, and not single types of receptors, are activated during occupational exposures to vibration because most of the hand-held vibratory tools generate accelerations over a broadband frequency range. Upon consideration that HTV from power tools determines psychophysical and physiological responses over a wide range of frequencies (33), it is hard to believe that a single frequency weighting is appropriate to predict the overall sensory response to vibration among humans. Since long-term exposure to vibration from power tools can lead to permanent impairment of tactile sensitivity [due to either anatomical loss of sensory afferents (32) or depression of the excitability of all types of tactile units (34)], on a clinical level, a comprehensive battery of quantitative sensory tests - and not a single test - is recommended to assess and quantify the overall sensory function among patients affected with neuropathies or at risk of developing neurological disorders (35).

\section{Limitations of the study}

Some potential sources of bias in this cohort study have been reported in previous papers $(5,7)$. Briefly, vibration was measured on the hand-held tools currently used by forestry and stone workers, and this may be a source of uncertainty for the estimation of vibration exposure over time. However, the weighted rms acceleration magnitudes of vibration measured in the tools of the present study are consistent with those reported in recent and past investigations and in vibration guidelines (36).

In this study, daily and total duration of exposure to vibration were quantified by means of questionnaire data or direct interview of employees and employers, so that recall bias cannot be excluded. To reduce, at least partially, this bias, a survey was conducted in the field by supervisors who measure the daily time the tool operators were exposed to the vibration according to a stopwatch method recommended by the EU guide on HTV (36). Moreover, questionnaire methods may offer a means for studying cumulative exposure over time, a variable which cannot be estimated by direct observations or measurements.

Over the follow-up period, there was no clear evidence of either leaving the cohort or change in vibration exposure among the HTV-exposed workers because of the onset or aggravation of sensory symptoms, even 
though feedback bias (ie, modification of exposure in symptomatic workers) cannot be completely ruled out.

In this study, 72 HTV-exposed workers and 39 controls did not participate in all follow-up surveys. Since retirement and change of residence were the major causes of dropping out of the study, it was assumed that the pattern of missing data during the follow-up was random, although this assumption could not be fully verified (7).

Other sources of uncertainties, such as the short duration of the follow-up time (three years) or the second power-time dependency used to estimate daily vibration exposure, have been discussed in detail elsewhere $(5,7)$.

\section{Concluding remarks}

The findings of this prospective cohort study showed significant dose-response relationships between measures of vibration exposure and outcomes of neurosensory disorders and reduced work ability among HTVexposed workers. Measures of daily vibration exposure calculated with alternative frequency weightings of acceleration magnitude provided the same predictions of the occurrence of finger numbness in the exposed workers.

\section{Acknowledgments}

The European Commission supported this research under the Quality of Life and Management of Living Resources program - Project No. QLK4-2002-02650 (VIBRISKS).

The authors declare no competing interests.

\section{References}

1. Bovenzi M. Exposure-response relationship in the hand-arm vibration syndrome: an overview of current epidemiology research. Int Arch Occup Environ Health. 1998;71:509-19. http://dx.doi.org/10.1007/s004200050316.

2. International Organization for Standardization (ISO). Mechanical vibration - measurement and evaluation of human exposure to hand transmitted vibration, part 1: general requirements. Geneva: ISO; 2001. ISO 5349-1.

3. Griffin MJ, Bovenzi M, Nelson CM. Dose-response patterns for vibration-induced white finger. Occup Environ Med. 2003;60:16-26. http://dx.doi.org/10.1136/oem.60.1.16.

4. Risks of Occupational Vibration Exposures (VIBRISKS). FP5 Project No. QLK4-2002-02650. European Commission Quality of Life and Management of Living Resources Programme. Southampton, UK: Human Factors Research Unit, Institute of Sound and Vibration Research, University of
Southampton [updated 28 February 2007; cited 1 April 2014].

Available from: http://www.vibrisks.soton.ac.uk.

5. Bovenzi M, Pinto I, Picciolo F, Mauro M, Ronchese F. Frequency weightings of hand-transmitted vibration for predicting vibration-induced white finger. Scand J Work Environ Health. 2011;37:244-52. http://dx.doi.org/10.5271/ sjweh.3129.

6. Mason HJ, Poole K, Elms J. Upper limb disability in HAVS cases - how does it relate to the neurosensory or vascular elements of HAVS. Occup Med. 2005;55:389-92. http:// dx.doi.org/10.1093/occmed/kqi076.

7. Bovenzi M. A prospective cohort study of exposure-response relationship for vibration-induced white finger. Occup Environ Med. 2010;67:38-46. http://dx.doi.org/10.1136/ oem.2009.046128.

8. Griffin MJ. Measurement, evaluation, and assessment of peripheral neurological disorders caused by hand-transmitted vibration. Int Arch Occup Environ Health. 2008;81:559-73. http://dx.doi.org/10.1007/s00420-007-0253-5.

9. Rempel D, Evanoff B, Amadio PC, de Krom M, Franklin G, Franzblau A, et al. Consensus criteria for the classification of carpal tunnel syndrome in epidemiologic studies. Am J Public Health. 1998;88:1447-51. http://dx.doi.org/10.2105/ AJPH.88.10.1447.

10. International Organization for Standardization (ISO). Human response to vibration - measuring instrumentation. Geneva: ISO; 2005. ISO 8041.

11. Pitts P. Evaluation of candidates for additional frequency weightings for hand-arm vibration measurement. Humanschwingungen. VDI-Berichte Nr. 2097. Würzburg: VDI Verlag; 2010. p. 125-34.

12. Dong RG, Welcome DE, Wu JZ. Frequency weightings based on biodynamics of fingers-hand-arm system. Ind Health. 2005;43:516-26. http://dx.doi.org/10.2486/indhealth.43.516.

13. Tominaga $Y$. New frequency weighting of hand-arm vibration. Ind Health. 2005;43:509-15. http://dx.doi.org/10.2486/ indhealth.43.509.

14. Directive 2002/44/EC of the European Parliament and the Council of 25 June 2002 on the minimum health and safety requirements regarding the exposure of workers to the risks arising from physical agents (vibration) (16th individual Directive within the meaning of Article 16(1) of Directive 89/391/EEC). Off J Eur Communities. L 117/13, 6.7.2002.

15. Twisk JWR. Applied longitudinal data analysis for epidemiology. A practical guide. Cambridge: Cambridge University Press; 2013. http://dx.doi.org/10.1017/ CBO9781139342834.

16. Cui J. QIC program and model selection in GEE analyses. Stata J. 2007;7:209-20.

17. Burnham KP, Anderson DR. Multimodel inference: understanding AIC and BIC in model selection. Sociol Methods Res. 2004;33:261-304. http://dx.doi. org/10.1177/0049124104268644.

18. Griffin MJ, Bovenzi M. The diagnosis of disorders caused by hand-transmitted vibration: Southampton Workshop 2000. Int 
Arch Occup Environ Health. 2002;75:1-5.

19. Cherniack M, Morse TF, Brammer AJ, Lundström R, Meyer $\mathrm{JD}$, Nilsson T, et al. Vibration exposure and disease in a shipyard: a 13-year revisit. Am J Ind Med. 2004;45:500-12. http://dx.doi.org/10.1002/ajim.20019.

20. Futatsuka M, Shono M, Sakakibara H, Quoc Quan P. Hand arm vibration syndrome among quarry workers in Vietnam. J Occup Health. 2005;47:165-70. http://dx.doi.org/10.1539/ joh.47.165.

21. Sauni R, Pääkkönen R, Virtema P, Toppila E, Uitti J. Doseresponse relationship between exposure to hand-arm vibration and health effects among metalworkers. Ann Occup Hyg. 2009;53:55-62. http://dx.doi.org/10.1093/annhyg/men075.

22. Edlund M, Burström L, Gerhardsson L, Lundström R, Nilsson T, Sandén $H$, et al. A prospective cohort study investigating an exposure-response relationship among vibration-exposed male workers with numbness of the hands. Scand J Work Environ Health. 2014;40:203-9. http://dx.doi.org/10.5271/ sjweh.3386.

23. Cederlund R, Nordenskiőld U, Lundborg G. Handarm vibration exposure influences performance of daily activities. Disabil Rehabil. 2001;23:570-7. http://dx.doi. org/10.1080/09638280010036535.

24. Sauni R, Virtema P, Pääkkönen R, Toppila E, Pyykkö I, Uitti J. Quality of life (EQ-5D) and hand-arm vibration syndrome. Int Arch Occup Environ Health. 2010;83:209-16. http://dx.doi. org/10.1007/s00420-009-0441-6.

25. Edlund M, Gerhardsson L, Hagberg M. Physical capacity and psychological mood in association with self-reported work ability in vibration-exposed patients with hand symptoms. J Occup Med Toxicol. 2012;7:22. http://dx.doi. org/10.1186/1745-6673-7-22.

26. van den Heuvel SG, van der Beek AJ, Blatter BM, Hoogendoorn WE, Bongers PM. Psychosocial work characteristics in relation to neck and upper limb symptoms. Pain. 2005;114:4753. http://dx.doi.org/10.1016/j.pain.2004.12.008.

27. Shiri R, Miranda H, Heliövaara, Viikari-Juntura E. Physical work load factors and carpal tunnel syndrome: a populationbased study. Occup Environ Med. 2009;266:368-73. http:// dx.doi.org/10.1136/oem.2008.039719.
28. van Rijn RM, Huisstede BMA, Koes BW, Burdorf A. Associations between work-related factors and the carpal tunnel syndrome - a systematic review. Scand J Work Environ Health. 2009;35:19-36. http://dx.doi.org/10.5271/ sjweh.1306.

29. Bovenzi M. Epidemiological evidence for new frequency weightings of hand-transmitted vibration. Ind Health. 2012;50:377-87. http://dx.doi.org/10.2486/indhealth. MS1382.

30. Johansson RS, Landström U, Lundström R. Responses of mechanoreceptive afferent units in the glabrous skin of the human hand to sinusoidal skin displacements. Brain Res. 1982;244:17-25. http://dx.doi.org/10.1016/00068993(82)90899-X

31. Johnson K. Neural basis of haptic perception. In: Pashler H, Yantis S, editors. Stevens' Handbook of Experimental Psychology, 3rd edition. Volume 1: Sensation and Perception. New York: Wiley; 2002. p. 537-83.

32. Govindaraju SR, Curry BD, Bain JLW, Riley DA. Nerve damage occurs at a wide range of vibration frequencies. Int J Ind Ergon. 2008;38:687-92. http://dx.doi.org/10.1016/j. ergon.2007.10.008.

33. Griffin MJ. Frequency-dependence of psychophysical and physiological responses to hand-transmitted vibration. Ind Health. 2012;50:354-69. http://dx.doi.org/10.2486/ indhealth.MS1379.

34. Lundström R. Responses of mechanoreceptive afferent units in glabrous skin of the human hand to vibration. Scand J Work Environ Health. 1986;12:413-6. http://dx.doi.org/10.5271/ sjweh.2121.

35. Shy ME, Frohman EM, So YT, Arezzo JC, Cornblath DR, Giuliani MJ, et al. Quantitative sensory testing: report of the therapeutic and technology assessment subcommitte of the America Academy of Neurology. Neurology. 2003;60:898-904. http://dx.doi.org/10.1212/01. WNL.0000058546.16985.11.

36. Griffin MJ, Howarth HVC, Pitts PM, Fischer S, Kaulbars $\mathrm{U}$, Donati $\mathrm{P}$, et al. Guide to good practice on whole-body vibration. European Commission Directorate General Employment, Social Affairs and Equal Opportunities (contract VC/2004/0341); 2006.

Received for publication: 1 October 2014 